\title{
Research on Dust Aerosol Particles Size Distribution
}

\author{
Mingxia Xiao ${ }^{1,2, a}$ Changhua $\mathrm{Lu}^{2, \mathrm{~b}}$ Haicheng Wei ${ }^{1, \mathrm{c}}$ Weiwei Jiang ${ }^{2, \mathrm{~d}}$ \\ ${ }^{1}$ School of Electrical and Information Engineering, Beifang University For Nationalities, Yinchuan, \\ Ningxia, China \\ ${ }^{2}$ School of Computer and Information, Hefei University of Technology,Hefei, Anhui, China \\ axiao_xiao963@163.com bwei_hc@nun.edu.cn Ich6208@163.com ${ }^{\mathrm{d}} \mathrm{cttjww@126.com}$
}

\begin{abstract}
According to the characteristics of Sand-dust aerosol in northwest of China, the Sand-dust aerosol particle size distributions have been measured. A great deal of data have been collected in different weather conditions, which include background, floating dust, blowing sand, and sand storm. The rules have been found out through statistical analysis. Sand aerosol concentration is changeable in different weather conditions and process. During the blowing sand and sand storm weather, aerosol concentration changes a lot, but during the floating dust weather, it changes a little. The stronger the aerosol concentration is, the more the number of aerosol particles $(\mathrm{d}>2.5 \mu \mathrm{m})$ is, and the more obvious changes occurs in the concentration of various diameter ranges. During different processes, coarse and fine particles have different contributions to the surface concentration. Through comparing the results, the wind speed is an important factor in weather conditions, and in different dust weathers, the PM1, PM2.5 and PM10 distribution different greatly.
\end{abstract}

Keywords: Sand-dust aerosol concentration, Size distribution, Weather condition

\section{Introduction}

Atmospheric aerosol refers to the whole dispersion system formed by the suspension of any solid or liquid particles in air. Although aerosol quality is only a small part in the whole air quality, it has an important influence on climate change, visibility change and human health, which is closely related with human activities [1]. Aerosols can affect climate through direct and indirect influences. Direct influence is the radiation imbalance caused by the scattering and absorption of solar radiation. The indirect influence is by changing the radiation characteristics of the cloud and change the radiation balance by developing the cloud microphysical properties [2-3]. Dust aerosol is the main component of tropospheric aerosol, which has significant effect on climate [4]. Due to the frequent dust weather in northern China, a large number of dust aerosols enter the atmosphere every spring, with the atmospheric circulation transported to densely populated areas, affecting and endangering the human environment and health, through the systematic analysis of the physical properties of dust aerosol, such as the concentration of dust aerosol particles and the particle spectrum distribution. The influence of dust aerosol on atmospheric environment can be studied quantitatively [5]. Yinchuan city is located in the east of Helan Mountain, between the Tengger Desert and $\mathrm{Mu}$ Us Desert, where the Yellow River cross through. It is necessary to study the physical properties of dust aerosol in Yinchuan area and obtain its characteristic data.

A lot of research work has been done on the monitoring and analysis of dust aerosol data, and many great progresses have been made. Christian C. Marchant uses mobile multi-wavelength scanning lidar to obtain the temporal and spatial characteristics of mass concentration of different types of particles [6]. Jugder and Dulam used smoke and aerosol Mie lidar measurements in Mongolia to detect burning dust and got biomass distribution [7]. Shin and Dong Ho measured the properties of marine boundary layer aerosols by using shipborne polarimetric lidar in coastal areas of Korea, and analyzed the influence of wind speed on optical properties [8]. At the same time, many domestic scholars have done a lot of related research work. Di Huige, Xin lantern etc. who were from Xi'an University of technology used Mie lidar detected the atmospheric in Xi'an [9]. Zhou Bi used the lidar data of 2006 to 2011 in cloudless climes, which from the semiarid climate and environment Observatory in Lanzhou University, combined the date of multi wavelength sun 
photometer between December 2006 to May 2006, and analyzed the distribution characteristics of aerosol optical thickness in Lanzhou [10]. He Qianshan used the micro pulse lidar data of urban environment meteorological in Shanghai center from March 2009 to February 2010, reveals that the characteristics of vertical distribution in Shanghai dry and damp haze through the analysis of the aerosol extinction coefficient and optical thickness, and analyzed the influences of relative humidity on dry and damp haze [11].

In the past, it is separated of sampling the different dust aerosol process, and the sampling time is relatively short. It was difficult to observe the whole process of dust weather completely. In this paper, we collected the dust particle spectrum data of March to April 2014, in Yinchuan, with different condition such as background atmosphere, dust, flying sand and sandstorms, statistical analyzed the instantaneous evolution characteristics in different weather conditions of sand dust aerosol particle spectrum, the proportion of the average spectrum distribution and different thickness of dust aerosol particles PM1, PM2.5 and PM10, and provides practical basis for numerical simulation of climate effect of dust aerosol radiation.

\section{Instruments and data}

Aerodynamic particle size and concentration distribution were measured by APS-3321 aerodynamic particle size analyzer. Aerosol particles can be restricted in the center of accelerated airflow by this equipment, measured the particle scattering of two orthogonal focused laser beam, and calculated the flight velocity of particle according to the measured time of flight. The velocity distribution of aerosol particles affected by particle size, smaller particles will get more speed, the calibration can be made by the relationship between particle velocity and particle size through styrene rubber ball [12-15]. With the help of the above mechanism, APS-3321 can establish the relationship between particle velocity and aerodynamic diameter. The precision of the test equipment are: the total particle concentration of which particle aerodynamic diameter are greater than $0.37 \mu \mathrm{m}$, observed particle concentration range are from $0.001 \mathrm{~cm}^{-3}$ to $104 \mathrm{~cm}^{-3}$. By the analysis and calculation of each data, many important information can be concluded such as the aerosol number concentration, surface area concentration, volume concentration and mass concentration with the particle size distribution etc..

The sampling point was set in Yinchuan, Ningxia (latitude $38^{\circ} 14^{\prime}$, longitude $106^{\circ} 16^{\prime}$ ), the sampling height was of about 20 meters from the ground, which is away from the sources of pollution. These conditions could reflect the situation of dust aerosols in Yinchuan. Instrument sampling occurs was be set in every 5 minutes and continuous sampling in observation time.

\section{Analysis of dust aerosol spectral characteristics}

\section{Analysis of dust aerosol instantaneous spectral characteristics}

Dust aerosol can be divided into three types of dust, blowing sand and dust storm [16]. During March to April in 2014, the data of atmospheric background has been sampled once, in dust weather with three times, in dust weather of twice and sandstorm weather of once, which has be showed in table 1.

Figure 1 shows the changes of dust particle number and instantaneous mass concentration during sand and dust storm weather conditions. In Figure 1, it is shown in $a$ and $b$ that the change of instantaneous number concentration and mass concentration were relatively flat in floating dust weather. It rises gradually to the maximum and then slowly decreases. With the small wind speed about $6.1 \mathrm{~m} / \mathrm{s}$ at that time, the corresponding airflow exchange is slow. During the process of blowing sand (Figure $1 \mathrm{c}, \mathrm{d}$ ), the instantaneous number concentration and mass concentration fluctuate gradually; with the measured wind speed was about $10.8 \mathrm{~m} / \mathrm{s}$. In Figure 1, e and f showed the sandstorm weather particle spectrum distribution. In the initial stage of sandstorm, the dust instantaneous number increases to the maximum immediately. While in the middle of the process, the particle number concentration decline. At the end of period and after the expiration of a period of 
time, the number concentration remained at a high level. In addition, during sandstorm it was measured that the wind speed was about $13.1 \mathrm{~m} / \mathrm{s}$, which means the wind speed is also one of the important factors determine the dust particle concentration.

Table 1 Observational data

\begin{tabular}{|c|c|c|}
\hline Observational time & $\begin{array}{l}\text { No. of } \\
\text { sample }\end{array}$ & Weather \\
\hline $3 / 1708: 00-11: 40$ & 45 & Blowing sand \\
\hline 3/17 12:05-3/18 01:00 & 156 & Floating dust \\
\hline 3/27 05:40-10:50 & 63 & Blowing sand \\
\hline $3 / 2711: 25-13: 45$ & 29 & Floating dust \\
\hline $4 / 112: 15-21: 40$ & 114 & Background Atmosphere \\
\hline $4 / 248: 00-18: 45$ & 130 & sand storm \\
\hline $4 / 2419: 10-21: 30$ & 29 & Floating dust \\
\hline
\end{tabular}

During the process of blowing sand and sand storm, the change of mass concentration and number concentration were quite obvious. As can be seen from table 1, dust generation is accompanied after the blowing sand and sandstorm. This is according to the decrease of wind speed, transportation of dust particles in the air is abate by wind, the air of dust particle concentration decreases, flying sand and dust storm slowly into the dust, and dust particle concentration is decreases, blowing sand or sandstorms turned to dust slowly. It is found that wind speed plays an important role in the state and motion of dust particles in air. According to the key effect of diameter less than $2 \mu \mathrm{m}$ particles of aerosol, makes diameter of $2 \mu \mathrm{m}$ as the boundary to study the dust particles under different weather conditions (particle diameter $\mathrm{d} \leq 2.0 \mu \mathrm{m}$ ) accounted for the ratio of the number concentration and mass concentration.

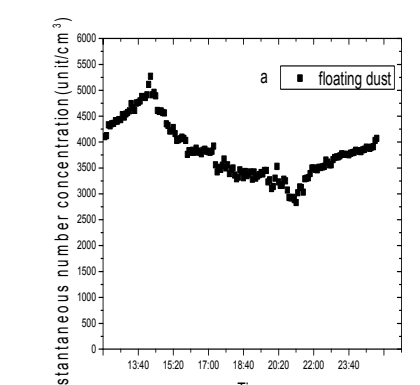

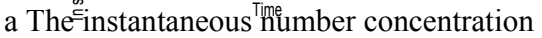
(floating dust)

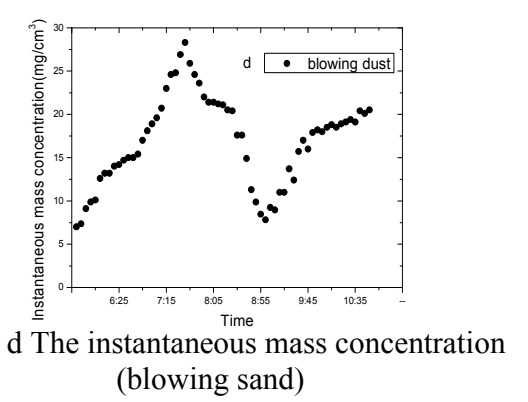

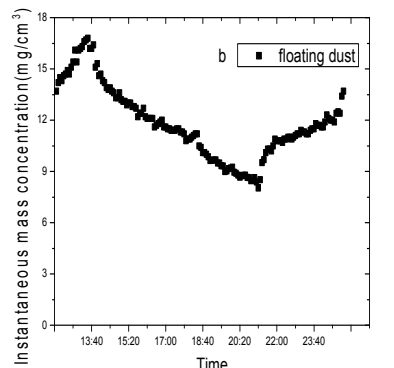

b The instantaneous mass concentration (floating dust)

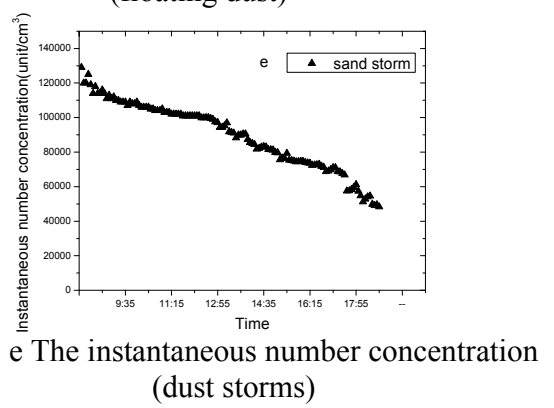

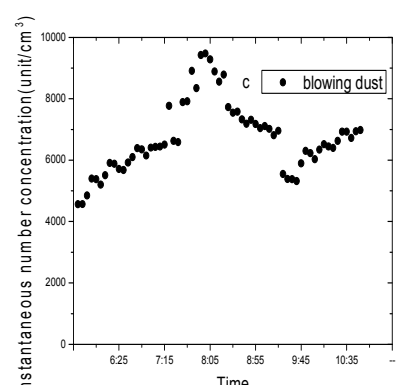

c The ${ }^{\stackrel{\infty}{*}}$ instantaneous number concentration (blowing sand)

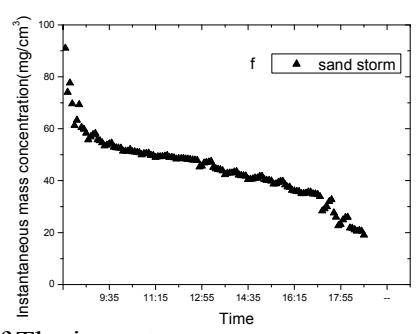

f The instantaneous mass concentration (dust storms)

Fig.1 Instantaneous sample number concentration and mass concentration with temporal variations

Figure 2 shows that under different dust weather conditions, the different ratio of aerosol concentrations with aerosol particle diameter $\mathrm{d} \leq 2.0 \mu \mathrm{m}$. This is because in the dust weather, although the number is smaller than the concentration of dust, but the wind speed in the dust weather is small, suspended dust in the air is mainly composed by the particles whose diameter are less or equal to $2 \mu \mathrm{m}$. With the sandstorm weather, the wind speed is big, the majority of airborne aerosols 
concentrated in diameter greater than or equal to $2 \mu \mathrm{m}$. In the end of dust and blowing sand process, the number of the ratio of particle diameter is less than or equal to $2 \mathrm{~m}$ particles gradually increased. At the end of sand and dust storm process, the particle number concentration ratio of particle diameter less than or equal to $2 \mu \mathrm{m}$ is close. This is because with the end of the dust weather, the wind speed becomes smaller, coarse particles will slowly subside; fine particles will be suspended in the air for some time.

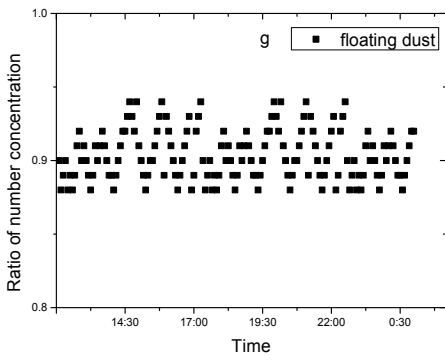

a Floating dust

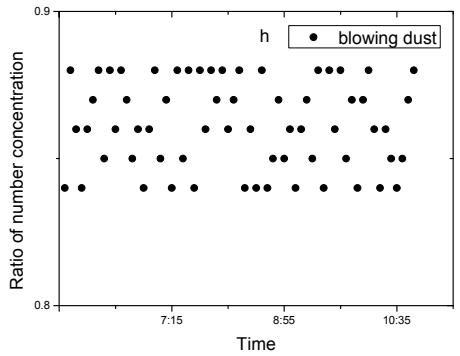

$\mathrm{b}$ blowing sand

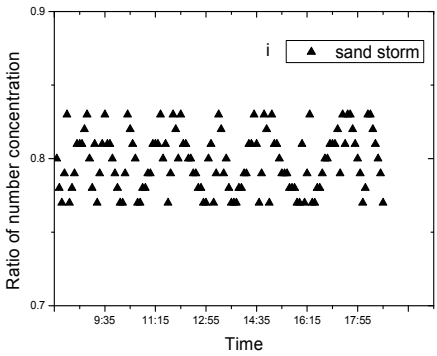

C sandstorms

Fig.2 Ratios of the dust particle number $(\mathrm{d} \leq 2.0 \mu \mathrm{m})$ to total aerosol particle in different weather

\section{Analysis of characteristics of dust aerosol average spectral distribution}

Floating dust, blowing sand and sandstorm weather phenomenon is different. The main dust particles are the dust and sand, the visibility is less than $10 \mathrm{~km}$. In blowing sand weather, the dust is formed by blowing sand form ground; the visibility is between $1-10 \mathrm{~km}$. And the sandstorm is dust weather phenomena caused by strong winds, the visibility within $1 \mathrm{~km}$. The visibility is even less than $500 \mathrm{~m}$ in the strong sandstorm [17].

The dust is often occurs after the sandstorm and blowing sand weather, the number and mass concentration of dust weather is far greater than it in the background weather(almost at 4-9 times), and the average concentration of sandstorm is even 44 times the background weather.

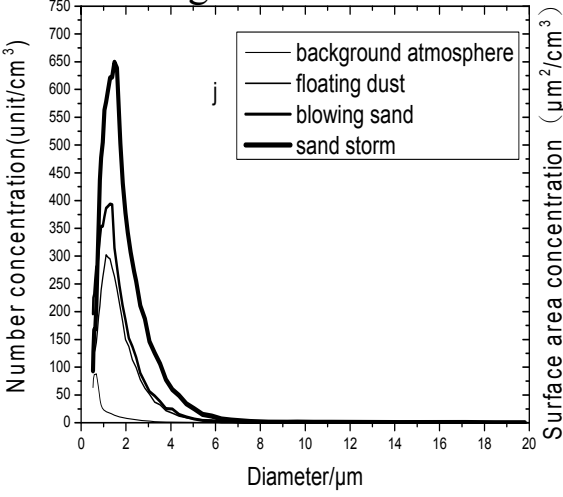

a The concentration spectrum of average

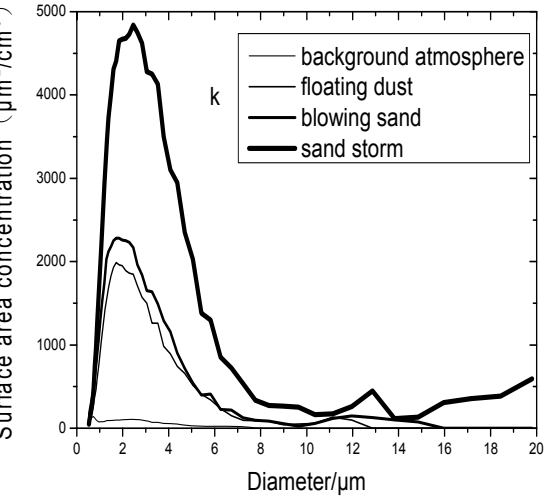

b The concentration spectrum of average surface area

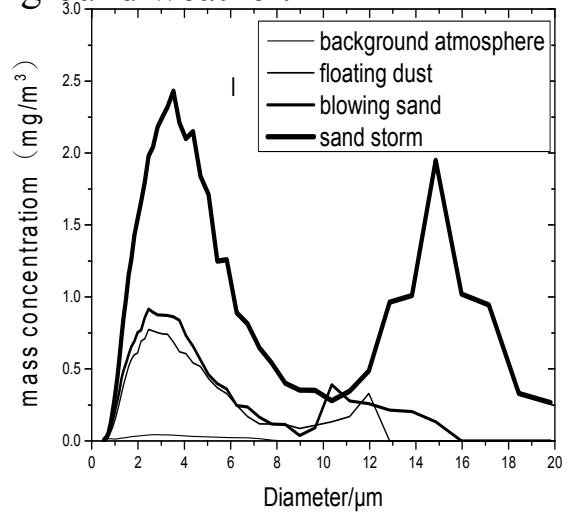

c The concentration spectrum of average mass

Fig.3 The average spectral distribution of the four weather phenomena

Figure 3 shows the average number of background air, floating dust, blowing sand and sandstorm aerosol particle concentration profiles are unimodal distribution. The peak of background atmosphere is around $0.7 \mu \mathrm{m}$, mostly concentrated in the region of particle diameter less than $2 \mu \mathrm{m}$, and it is almost zero with size more than $10 \mu \mathrm{m}$. The peak of floating dust weather is around at $1.1 \mu \mathrm{m}$, mostly concentrated in the region of particle diameter is less than $2.5 \mu \mathrm{m}$. The peak of blowing sand weather is around at $1.3 \mu \mathrm{m}$, mostly concentrated in the region of particle diameter is less than $5 \mu \mathrm{m}$. The peak of sandstorm weather is around at $1.5 \mu \mathrm{m}$, mostly concentrated in the region of particle diameter is less than $10 \mu \mathrm{m}$.

To the concentration spectrum of average surface area, background spectrum makes a unimodal distribution, the peak center is around $0.7 \mu \mathrm{m}$, and in floating dust, blowing sand and sandstorm aerosol particles it were distributed as bimodal, the peak center of blowing sand was at $1.8 \mu \mathrm{m}$ and $12 \mu \mathrm{m}$ respectively; the sandstorm peak center respectively in $2.5 \mu \mathrm{m}$ and $12.9 \mu \mathrm{m}$, and the average surface area concentration profiles are rising, but not to the point where it falls low to 0 , which shows 
that the sandstorm weather there are large particles, although the number is not so big, but still makes contribution to a higher concentration on the surface area.

To the concentration spectrum of average mass, atmospheric background spectrum shows a unimodal distribution, the peak center is around $2.8 \mu \mathrm{m}$, while in floating dust, blowing sand and sandstorm aerosol particles shows a bimodal distribution, the peaks center of floating dust are around $2.5 \mu \mathrm{m}$ and $12 \mu \mathrm{m}$, the peaks center of blowing sand are around $2.5 \mu \mathrm{m}$ and $10.4 \mu \mathrm{m}$, and the peaks center of sandstorm are around $3.5 \mu \mathrm{m}$ and $14.9 \mu \mathrm{m}$,

By contrast, it is shown that with the sand and dust weather condition although the number of large particle size is not large and makes little influence to the logarithmic concentration, but it has great influence on the mass concentration. Moreover, from the average mass concentration spectrum, the value of PM2.5 is very large in the dust weather, which makes serious air pollution.

\section{Concentration analyses of PM1, PM2.5 and PM10 in the process of dust weather}

Solid particles or liquid droplets dust particle size is usually denoted as PM, particle aerodynamic equivalent air particle size less or equal $1 \mu \mathrm{m}$ in ambient air is PM1. These particle size can easily enter the lungs; and the particle size less than $2.5 \mu \mathrm{m}$ is commonly referred PM2.5. Those whose particle diameter less than or equal to $10 \mu \mathrm{m}$ is PM10, which is inhalable particles or dust. Overall, particle size less than $10 \mu \mathrm{m}$ with small particle size, are considered high toxicity, long residence time, distance transportation and other characteristics, has a tremendous impact on the air quality of the environment and people's health.

Table 2 The particles mass concentration of diameter ratios to the total mass concentration in different weather

\begin{tabular}{llllll}
$(\mathrm{d} \leq 1 \mu \mathrm{m}, 2.5 \mu \mathrm{m}, 10 \mu \mathrm{m})$ & & & PM1 & PM2.5 & PM10 \\
\hline Background & 3.3 & 1.1 & 0.15 & 0.5 & 1.08 \\
Floating dust & 6.1 & 10.6 & 0.42 & 4.6 & 10.1 \\
Blowing sand & 10.8 & 18.4 & 0.59 & 7.83 & 17.2 \\
Sandstorm & 13.1 & 44.3 & 0.61 & 13.2 & 40.3 \\
\hline \hline
\end{tabular}

As can be seen on Table 2, with the background weather, the values of PM1, PM2.5, PM10 are relatively small, while the percentage of total mass concentration is relatively large. This is due to the wind speed is small in the background weather, the aerosol in the air are mainly fine particles, mainly composed with soil dust and industrial emissions, where human activities are the main causes. In the weather of floating dust, blowing sand and sandstorm process, the values of PM1, PM2.5, PM10 are increased, but the percentage of the total mass concentration is reduced. This is because in the dust weather, with the increase of wind speed, the quality and quantity of the coarse particles in the air particles increases, though mainly composed with fine particles, the proportion of coarse particles is increased, and the main source is from transportation distance of the dust. This indicates that wind speed is an important factor of aerosol concentration.

\section{Conclusions}

Based on the analysis of aerosol particle data under different intensity dust weather conditions in Yinchuan area, we can obtain:

(1) The evolution characteristics of dust aerosol concentration are different under different dust weather conditions. In the initial stage of sandstorm, the instantaneous concentration of dust aerosol suddenly rises, then shows a decline, however still keeps high concentration. During the process of blowing sand, the concentration increases and then decreases gradually. In the process of floating dust, the concentration changes slowly, rising to the maximum gradually and then slowly decrease.

(2) The average number of floating dust, blowing sand and sandstorm aerosol particle concentration distribution was unimodal type, the average surface area concentration spectrum was bimodal type, and the average concentration was bimodal type. The peak centers are different under different weather conditions.

(3) During the process of floating dust, blowing sand and sandstorm, PM1, PM2.5, PM10 value 
is increased, but the percentage of their total mass concentration is reduced. This is due to the dust weather, with the increase of wind speed; the quality and quantity of coarse particles were increase too. Though fine particles were the main part in the air, the proportion of coarse particles increased, and main source is due to the transportation distance of the dust.

\section{Acknowledgment}

This work is supported by the National Natural Science Foundation (No. 61461001).

\section{References}

[1]Li Suwen, Si Fuqi, Zhao Xin. Retrieval method of near ground aerosol extinction coefficient based on remote sensing[J]. Journal of Electronic Measurement and Insturment, 2009, 23(9):69-73

[2]Paltridge Pratt. The radiative process of meteorology and climatology. Beijing: Science Press, 1981: 142-154.

[3] Hu Z Y, Huang R H, Wei G A. The variation of ground meteorological elements and characteristics of the surface energy balance in Dunhuang when sand storm transit in the June 4, 2000[J]. Atmospheric Science, 2002, 26(1): 127.

[4]Gu Y D, Niu S J. Dust aerosol instantaneous spectral analysis and fitting in Helan mountain area[J]. Meteorological Journal in Nanjing, 2006, 29(4): 500-506.

[5]Gu Y D, The Analysis and Fitting of the Instantaneous Size Distributions of Sand Aerosol Particles[D], Nanjin University of Information Engneering,2006-08

[6] Christian C. Marchant, Algorithm Development of the Aglite-Lidar Instrument [D], Utah: UTAH State University, 2008.

[7] Jugder, Dulam, Dust, biomass burning smoke, and anthropogenic aerosol detected by polarization-sensitive Mie lidar measurements in Mongolia , Atmospheric Environment, v 54, $\mathrm{p}$ 231-241, July 2012

[8] Shin, Dong Ho, Influence of wind speed on optical properties of aerosols in the marine boundary layer measured by ship-borne DePolarization Lidar in the coastal area of Korea, Atmospheric Environment, v 83, p 282-290, February 2014

[9]Di Huige, Hua Dengxin, Wang Yufeng, et al. Investigation on the correction of the Mie scattering lidar's overlapping factor and echo signals over the total detection range[J], Acta Phys. Sin., 2013,62(9): 094215-1-094215-5

[10]Zhou Bi, Zhang Lei, Jiang Deming,et al. Analysis of Aerosol Optical Depth over Lanzhou Based on Lidar Measurement[J], Journal of Arid Meteorology, 2013,31( 4):666-671

[11]He Qianshan, Pan Hu,Huang Ying,et al. Comparison of the extinction of aerosols and humidity influence between dry and damp haze periods in Shanghai[J], Journal of Lanzhou University (Natural Sciences), 2013,49(4):497-503

[12] Wilson J.C, Liu Y H, et al. aerodynamic particle size measurement by laser-doppler velocimetry[J]. Journal of Aerosol Science, 1980. 11(2): 139-150.

[13] Leith D, TM P. Concentration measurement and counting efficiency of the aerodynamic particle sizer 3321[J]. J Aerosol Sci, 2003, 34(5): 627-634.

[14] Dahneke B. Sampling and analysis of suspended particles and vapors by continuum source particle beams. AIChE Symp Ser, 1980, 76: 134-143.

[15] Dongho Park, Yong-Ho Kim, Chul Woo Park, et al. New bio-aerosol collector using a micromachined virtual impactor[J]. Journal of Aerosol Science, 2009, 40(5): 415-422.

[16] Ma J F, Chen F Y. Discussion of causes and Observations of blowing sand and floating dust[J]. Meteorological science and technology in Zhejiang, 2003, 22(1): 44-46. 
[17] Clayton C A, Perritt R L, Pellizzari E D, et al. Particle total exposure assessment methodology (PTEAM) study : distributions of aerosol and elemental concentrations in personal, in door, and outdoor air samples in a sout Analysis hern California community[ J]. Journal of Exposure and Environmental Epidemiology, 1993 3: 227 